\title{
PIBID E EDUCAÇÃO FÍSICA - TENSÕES DE UMA FORMAÇÃO DOCENTE QUE SE CONSTITUI NO ESCOLAR
}

\author{
Dinah Vasconcellos Terra ${ }^{\mathrm{i}}$ \\ Rosa Malena Carvalhoi
}

\begin{abstract}
Resumo: Participar de produção coletiva, aproximando o que a educação física realiza no PIBID, destacando a formação inicial e continuada de professores, é tarefa que requer diversos esforços. Especialmente quando ideias hegemônicas naturalizam a vida e, com isso, as práticas corporais são percebidas como expressão máxima dessa ideia. Por isso, caracterizamos essa prática pedagógica pela perspectiva da cultura corporal e, como esse paradigma vem oportunizando organizar seus conteúdos no escolar. No movimento de pensar sua invenção em um conjunto de tensões, apresentamos os compromissos e intenções que fizeram o Instituto de Educação Física da Universidade Federal Fluminense compor, desde 2011, um programa que proporciona perceber a escola como eixo articulador da formação docente.
\end{abstract}

Palavras-chave: Educação física escolar; PIBID; Cultura Corporal; Formação docente.

\section{PIBID Y EDUCACIÓN FÍSICA - TENSIONES DE UNA FORMACIÓN DOCENTE EN LA ESCUELA}

Resumen: Unirse a una producción colectiva, con lo que la educación física desarrolla en el PIBID, destacando la formación inicial y continuada del profesorado, requiere diversos esfuerzos. Especialmente cuándo las ideas hegemónicas naturalizan la vida y, con eso, las prácticas corporales son percibidas como expresión de esa idea. Aquí, caracterizamos esa práctica pedagógica por la perspectiva de la cultura corporal $\mathrm{y}$, como proporciona la organización de los contenidos en la escuela. En el movimiento de pensar suya invención en un conjunto de tensiones, presentamos los compromisos e intenciones que hicieran lo Instituto de Educación Física da Universidad Federal Fluminense componer, desde 2011, un programa que trae oportunidad de percibir la escuela como eje de la formación del profesorado.

Palabras-clave: Educación física escolar; PIBID; Cultura Corporal; Formación del profesorado.

\section{O PIBID em um projeto de formação de professores - tensões à sua manutenção}

O Programa Institucional de Bolsa de Iniciação à Docência (PIBID) é um Programa da Coordenação de Aperfeiçoamento de Pessoal de Nível Superior (CAPES), criado atendendo o decreto $n^{\circ} 6.755$ de 2009, que institui a Política Nacional de Formação de Profissionais do 
Magistério da Educação Básica para incentivar a formação de profissionais do magistério para atuar na educação básica pública.

O principal objetivo do programa é contribuir para a valorização do magistério elevando a qualidade da formação inicial de professores e promovendo a aproximação do ensino superior com a educação básica visto que seus participantes são: os alunos dos cursos de licenciatura, os professores das escolas parceiras de uma determinada área de conhecimento que recebe os alunos e, os professores das instituições de ensino superior dos cursos de formação de professores.

O lançamento da primeira chamada pública do PIBID ocorreu em 12 de dezembro de 2007, mediante Edital MEC/CAPES/FNDE 01/2007. Poderiam apresentar propostas as instituições federais de ensino superior e os centros federais de educação tecnológica que possuíssem cursos de licenciatura com avaliação satisfatória no Sistema Nacional de Avaliação da Educação Superior, na forma da Lei 10.861, de 14 de abril de 2004. Além disso, deveriam ter convênio e/ou acordo de cooperação com as redes de educação básica pública dos Municípios, dos Estados ou do Distrito Federal.

Em setembro de 2009, foi publicada a Portaria 122 que instituiu o PIBID no âmbito da CAPES e nesse mesmo mês e ano, foi divulgado o segundo edital (CAPES/DEB 02/2009), assinalando as diretrizes norteadoras para a apresentação de propostas pelas instituições de ensino superior. No ano seguinte, abril de 2010, foi publicado o Edital 18/2010 voltado especificamente para as Instituições de Ensino Superior Municipais e Comunitárias e não substituiu a anterior, aumentando o crescimento do programa em $30 \%$.

Em 15 de dezembro de 2010 foi assinado mais um edital - 01/2011, que foi lançado oficialmente no dia 03 de janeiro de 2011, com previsão de início para abril desse ano.

A chamada do Edital 11/2012, realizada em 19 de março de 2012, apresentou um aspecto diferenciado dos anteriores, que foi a referência aos marcos legais do PIBID. A análise desse edital evidencia que ele foi lançado para promover o avanço do programa ampliando, principalmente, o número de bolsas. O Edital de 02 de agosto de 68/2013 ratifica que o PIBID avançou e caminhava para a sua consolidação como uma forte estratégia de formação inicial de professores no Brasil alcançando a oferta de 72.000 bolsas. Segundo Gatti et all (2014) o programa alcança em cinco anos uma ampliação que ultrapassa as bolsas de Iniciação Científica (PIBIC) do Ministério de Ciência de Tecnologia em quinze anos de existência, passando a ser reconhecido no seu crescimento com caráter de consolidação. 
A Portaria CAPES nº 96, de 18 de julho de 2013, que balizou o Edital 68/2013 evidencia a qualidade, como também a organização de atos regulatórios, inclusive alterando a LDB - Lei de Diretrizes e Bases da Educação nacional No 9.394/1996, com o finalidade de garantir a sua continuação, assegurando-o como política pública e não política de governo. Destacamos especificamente ao Título VI - Dos Profissionais da Educação, Art. 62, Parágrafo $5^{\circ}$ que diz:

A União, o Distrito Federal, os Estados e os Municípios incentivarão a formação de profissionais do magistério para atuar na educação básica pública mediante programa institucional de bolsa de iniciação à docência a estudantes matriculados em cursos de licenciatura, de graduação plena, nas instituições de educação superior (Incluído pela Lei no 12.796, de 2013) (- BRASIL: LDB $\left.\mathrm{N}^{\circ} 9.394 / 1996\right)$

A trajetória apresentada acima demarca o percurso legislativo do PIBID, o que caracteriza, também, uma ampliação - possivelmente pela grande demanda reprimida de projetos desta natureza no âmbito do Ministério da Educação (MEC). A resposta da grande adesão das instituições formadoras representa a necessidade de qualificar a formação docente, anunciada em diversos espaços acadêmicos, mas de pouco retorno por parte da organização de políticas nessa natureza. Os seminários internos - com as instituições participantes e outras não participantes desse programa - em âmbito nacional, por meio dos encontros demonstra a potencialidade do programa e sua capacidade de geral e socializar experiências e produção necessária no âmbito da formação e valorização do magistério.

De 2007 a 2013 (ano do último edital), os objetivos do projeto sofreram alterações incorporando e/ou retirando questões significativas e de avanços relevantes no processo de formação dos futuros professores. Aqui consideramos não os aspectos legislativos, mas o que representa os objetivos do programa.

O quadro abaixo (e os destaques em itálico no mesmo) permite um panorama destas alterações e consequente análise das mudanças, as quais alternam o perfil de uma especificidade centrada em ações na escola como espaço de formação; passando para contribuir na melhoria da escola pública a partir de avaliações externas nacionais do desempenho dos estudantes das escolas; reconhecimento dos professores das escolas como co-formadores e; posterior divisão da responsabilidade da formação no projeto para as instituições formadoras tendo em vistas a permanente busca de princípios que qualifiquem o trabalho docente. 


\begin{tabular}{|c|c|}
\hline $\begin{array}{l}\text { Edital } \\
2007\end{array}$ & $\begin{array}{l}\text { - incentivar a formação de professores para a educação básica, especialmente } \\
\text { para o ensino médio; } \\
\text { - valorizar o magistério, incentivando os estudantes que optam pela carreira } \\
\text { docente; } \\
\text { - promover a melhoria da qualidade da educação básica; } \\
\text { - promover a articulação integrada da educação superior do sistema federal com } \\
\text { a educação básica do sistema público, em proveito de uma sólida formação } \\
\text { docente inicial; } \\
\text { - elevar a qualidade das ações acadêmicas voltadas à formação inicial de } \\
\text { professores nos cursos de licenciaturas das instituições federais de educação } \\
\text { superior; } \\
\text { - estimular a integração da educação superior com a educação básica no ensino } \\
\text { fundamental e médio, de modo a estabelecer projetos de cooperação que elevem } \\
\text { a qualidade do ensino nas escolas da rede pública; } \\
\text { - fomentar experiências metodológicas e práticas docentes de caráter inovador, } \\
\text { que utilizem recursos de tecnologia da informação e da comunicação, e que se } \\
\text { orientem para a superação de problemas identificados no processo ensino- } \\
\text { aprendizagem; } \\
\text { - valorização do espaço da escola pública como campo de experiência para a } \\
\text { construção do conhecimento na formação de professores para a educação } \\
\text { básica; } \\
\text { - proporcionar aos futuros professores participação em ações, experiências } \\
\text { metodológicas e práticas docentes inovadoras, articuladas com a realidade local } \\
\text { da escola. }\end{array}$ \\
\hline $\begin{array}{l}\text { Edital } \\
2009\end{array}$ & $\begin{array}{l}\text { - incentivar a formação de professores para a educação básica, contribuindo para } \\
\text { a elevação da qualidade da escola pública; } \\
\text { - valorizar o magistério, incentivando os estudantes que optam pela carreira } \\
\text { docente; } \\
\text { - elevar a qualidade das ações acadêmicas voltadas à formação inicial de } \\
\text { professores nos cursos de licenciatura das instituições públicas de educação } \\
\text { superior; } \\
\text { - inserir os licenciandos no cotidiano de escolas da rede pública de educação, } \\
\text { promovendo a integração entre educação superior e educação básica; } \\
\text { - proporcionar aos futuros professores participação em experiências } \\
\text { metodológicas, tecnológicas e práticas docentes de caráter inovador e } \\
\text { interdisciplinar e que busquem a superação de problemas identificados no } \\
\text { processo de ensino-aprendizagem, levando em consideração o IDEB e o } \\
\text { desempenho da escola em avaliações nacionais, como Provinha Brasil, Prova } \\
\text { Brasil, SAEB, ENEM, entre outras; } \\
\text { - incentivar escolas públicas de educação básica, tornando-as protagonistas nos } \\
\text { processos formativos dos estudantes das licenciaturas, mobilizando seus } \\
\text { professores como co-formadores dos futuros professores. }\end{array}$ \\
\hline $\begin{array}{l}\text { Edital } \\
2010\end{array}$ & Igual 2009 \\
\hline
\end{tabular}




\begin{tabular}{|l|l|}
\hline $\begin{array}{l}\text { Edital } \\
2011\end{array}$ & Igual 2009 \\
\hline $\begin{array}{l}\text { Edital } \\
2012\end{array}$ & Igual 2009 \\
\hline $\begin{array}{l}\text { Edital } \\
2013\end{array}$ & $\begin{array}{l}\text { - incentivar a formação de docentes em nível superior para a educação básica; } \\
\text { - contribuir para a valorização do magistério; } \\
\text { - elevar a qualidade da formação inicial de professores nos cursos de } \\
\text { licenciatura, promovendo a integração entre educação superior e educação } \\
\text { básica; } \\
\text { - inserir os licenciandos no cotidiano de escolas da rede pública de educação, } \\
\text { proporcionando-lhes oportunidades de criação e participação em experiências } \\
\text { metodológicas, tecnológicas e práticas docentes de caráter inovador e } \\
\text { interdisciplinar que busquem a superação de problemas identificados no } \\
\text { processo de ensino aprendizagem; } \\
- \text { incentivar escolas públicas de educação básica, mobilizando seus professores } \\
\text { como co-formadores dos futuros docentes e tornando-as protagonistas nos } \\
\text { processos de formação inicial para o magistério; } \\
- \text { contribuir para a articulação entre teoria e prática necessárias à formação } \\
\text { dos docentes, elevando a qualidade das açães acadêmicas nos cursos de } \\
\text { licenciatura; } \\
- \text { contribuir para que os estudantes de licenciatura se insiram na cultura } \\
\text { escolar do magistério, por meio da apropriação e da reflexão sobre } \\
\text { instrumentos, saberes e peculiaridades do trabalho docente. } \\
\text { Art. } 4^{\circ} \text { - Portaria Capes no 96, de 18 de julho de 2013 }\end{array}$ \\
\hline
\end{tabular}

As alterações nos objetivos do projeto foram acompanhadas com a inserção nos diferentes níveis de ensino como podemos observar no quadro abaixo. O PIBID inicia com foco (e com objetivo central) na falta de professores para o ensino médio, o que vai caracterizar o projeto centrado nesse nível de ensino - como podemos ver no primeiro objetivo no quadro acima. O que se constata e analisa nestes anos de projeto foi à ampliação para todos os níveis de ensino e modalidades como licenciaturas interculturais (formação de professores indígenas); licenciaturas em educação do campo, para comunidades quilombolas e educação de jovens e adultos e; projetos interdisciplinares.

\begin{tabular}{|l|l|}
\hline Edital 2007 & $\begin{array}{l}\text { Ensino médio: física; química; matemática; biologia; } \\
\text { Anos finais do ensino fundamental: ciências; e matemática; } \\
\text { Forma complementar: letras (língua portuguesa); educação musical e } \\
\text { artística; e demais licenciaturas. }\end{array}$ \\
\hline Edital 2009 & $\begin{array}{l}\text { Para o ensino médio: Física; Química; Filosofia; Sociologia; Matemática; } \\
\text { Biologia; Letras-Português; Pedagogia; licenciaturas com denominação especia }\end{array}$ \\
\hline
\end{tabular}




\begin{tabular}{|c|c|}
\hline & $\begin{array}{l}\text { que atendam a projetos interdisciplinares ou novas formas de organização do } \\
\text { ensino médio. } \\
\text { Para o ensino fundamental: Pedagogia, com destaque para prática em classes } \\
\text { de } \\
\text { alfabetização; Ciências; Matemática; Educação Artística e Musical; licenciatura } \\
\text { com denominação especial que atendam a projetos interdisciplinares ou novas } \\
\text { formas de } \\
\text { organização do ensino fundamental. } \\
\text { De forma complementar: Letras - Língua Estrangeira; licenciaturas } \\
\text { interculturais (formação de professores indígenas); licenciaturas em educação } \\
\text { do campo, para comunidades quilombolas e educação de jovens e adultos; } \\
\text { demais licenciaturas, desde que justificada sua necessidade social no local ou } \\
\text { região. }\end{array}$ \\
\hline Edital 2010 & Igual a 2009 incluindo a educação infantil. \\
\hline Edital 2011 & Edital complementar igual ao 2010 \\
\hline Edital 2012 & Edital complementar igual ao 2010 \\
\hline Edital 2013 & $\begin{array}{l}\text { Área de conhecimento: Artes Plásticas e Visuais; Biologia; Ciências; Ciências } \\
\text { Agrárias; Ciências Sociais; Dança; Educação Especial; Educação Física; } \\
\text { Enfermagem; Ensino Religioso; Filosofia; Física; Geografia; História; } \\
\text { Informática; Letras - Alemão; Letras - Espanhol; Letras - Francês; Letras - } \\
\text { Inglês; Letras - Italiano; Letras - Português; Matemática; Música; Pedagogia; } \\
\text { Psicologia; Química; Teatro; Interdisciplinar. } \\
\text { Níveis de ensino: Educação Infantil, Ensino Fundamental e Ensino Médio, } \\
\text { inclusive a Educação Profissional Técnica de Nível Médio. } \\
\text { Portaria Capes nº 96, de } 18 \text { de julho de } 2013 \text {. }\end{array}$ \\
\hline
\end{tabular}

Ainda que o projeto pudesse incluir algumas áreas, no item formação complementar e, isso poderia pesar no processo de avaliação e consequente aprovação, esse fato causou leituras e atitudes diferentes nas instituições formadoras na organização do projeto. Várias instituições não propuseram a inclusão de outras áreas com receio de que, dependendo da proposta, se poderia interpretar maior ou menor o valor as áreas prioritárias do projeto e, com isso, a rejeição do mesmo. A área da Educação Física, por exemplo, inserida no item formação complementar teve participação em quatro projetos institucionais no segundo edital, em parceria com Português/Letras e Artes.

A divulgação das ações do projeto nos espaços acadêmicos chama a atenção e mobiliza a comunidade científica na área da formação de professores, por entender que todas as áreas de conhecimento são relevantes no processo de formação dos estudantes das escolas públicas. O 
reconhecimento da dimensão do programa com impacto relevante na formação de professores possibilita, como vimos no quadro acima, a ampliação para todas as áreas de conhecimento e níveis de ensino, eliminando assim alguns desconfortos interno nas instituições participantes contemplando assim aquelas áreas ausentes no início do programa.

Mesmo considerando pontos críticos do programa como as poucas formas efetivas e distantes da própria proposta do PIBID (nesse caso falta de atuação efetiva na escola e nas salas de aula) de alguns projetos (GATTI et all, 2014), avaliamos que a trajetória do PIBID, a partir dos documentos apresentando até o momento, foi de constante reorganização e reorientação para que o programa alcançasse cada vez mais relevância no cenário da formação de professores.

Essa condição se concretizou porque a dinâmica da coordenação nacional do programa, na época e até 2014, manteve diálogo, por meio de reuniões sistemáticas, com os coordenadores institucionais, avaliando as contribuições destes e reconhecendo, nos diferentes cotidianos de seu desenvolvimento, buscar um tipo de organização que valorizasse e respeitasse as problemáticas regionais, mas que tivesse como princípio um projeto de formação de professores em que a escola seja o lócus da vivencia, problematização e reflexão da formação. Acompanhando esse princípio, e se de fato compreendemos a escola como lugar privilegiado para a formação inicial, talvez seja necessário, segundo Nóvoa (2009),

(...) devolver a formação de professores aos professores, porque o reforço de processos de formação baseadas na investigação só faz sentido se eles forem construídos dentro da profissão. (...) Nestes anos em que transitamos de aluno para professor é fundamental consolidar as bases de uma formação que tenha como referência lógicas de acompanhamento, de formação em situação, de análise da prática e de integração na cultura profissional docente (p.6).

O momento que demarca essa dinâmica é materializado na Portaria CAPES nº 96 , de 18 de julho de 2013. Fruto de várias discussões, a portaria estabelece uma organização e encaminhamento para um projeto de formação de professores capaz de mobilizar e criar consensos, naquele momento, consolidando o PIBID por quatro anos. Entretanto, a manutenção dessa perspectiva começa a ser interrompida no final de 2014, início de 2015, com trocas da coordenação nacional. O ano de 2015, em consonância com os descompassos vividos em outros âmbitos no país o projeto passa por tensões que reflete no seu desenvolvimento nas instituições participantes. 
Vários problemas como, por exemplo, o bloqueio dos recursos de custeios para compra de material e demais atividades para as escolas cumprir o planejamento das ações no projeto, dificulta sua execução, sendo necessário redefinir as estratégias de trabalho compatível com os objetivos iniciais. Vivenciamos o ano de 2015 com inúmeras investidas na descaracterização do programa, assim como muitas incertezas de sua continuidade. $\mathrm{O}$ anuncio de seu término e a grande mobilização nacional dos participantes para a permanência do PIBID até a chegada de nova Portaria No 46, de 11 de abril de 2016, destituindo a anterior com nova chamada, contrariando os princípios de uma formação de professores que se vinha construindo e tentando se consolidar com todos os problemas que ainda se precisa enfrentar ou superar.

No turbilhão do cenário político nacional e na especificidade das ações no Ministério da Educação (MEC) e na CAPES e, sem grandes análises para constatar os motivos, essa última Portaria é revogada. Se por um lado, a oscilação das incertezas descritas acima, nos releva as fragilidades e desafios que, ainda, precisamos enfrentar nesse país na formação de professores, por outro é preciso aprofundar em estudos e pesquisas que evidencie os impactos do projeto, ciente das já existentes em dissertações, teses e avaliação encomendada pelo MEC realizada por Gatti et all em 2013 e publicada em 2014.

O que está em jogo nessa descrição não é apenas a manutenção ou não do PIBID como política pública. Mas, sua trajetória demarca a necessidade de um diálogo nacional das potencialidades, fragilidades e desafios da formação de professores no país. Os diferentes modelos, concepções e ações desenvolvidas nos vários projetos institucionais precisam ser compreendidos nas especificidades dos contextos que são realizadas. Também é preciso, em se tratando de políticas educacionais, entender que não há linearidade possível em nenhum contexto. Acreditamos que devemos focalizar as implicações dos objetivos das políticas educacionais em termos de equidade e inclusão e, portanto, aprender com as práticas do PIBID dimensionando a formação desejada de maneira que os princípios e concepções deste alcancem os cursos de formação de formação.

A partir desta análise, localizamos o PIBID da UFF, o qual teve início em 2009 e hoje está localizado em cinco campi, totalizando cerca de 1000 bolsistas com o objetivo de preparar professores para que construam conhecimentos a partir de suas experiências profissionais por meio do trabalho coletivo, compartilhando soluções para os desafios cotidianos inseridos na cultura da docência. 
Ainda que sua ampliação tenha ocorrido ao longo dos anos, o desafio de um projeto desta dimensão nos coloca, também, frente a processos de formação diferentes internamente. Mas o que se busca acompanhar por meio de relatórios, seminários, reuniões especificas com grupos de participantes e seminários internos, é identificar a existência da parceria escola universidade, por entender que a duas instituições de níveis educacionais distintos, dialogando e pensando coletivamente como enfrentar os problemas cotidianos, superando os modelos convencionais de formação de professores. Sobretudo por reconhecermos que o conhecimento da escola como legítimo nesse processo formativo é necessário quando se deseja assumir e acreditar tanto num projeto de formação de professores de qualidade para escola pública, bem como da urgente valorização do magistério.

A problematização da manutenção do PIBID/UFF foi tensionada a partir do contexto nacional. Entretanto, ainda que tal situação tenha criado descompassos na conjuntura política de suas ações, este não perdeu o compromisso com as condições para um processo de formação conseqüente no desenvolvimento profissional dos futuros professores. Ao contrário, o PIBID/UFF vem demonstrando uma

(...) capacidade formadora potencializando o rompimento de barreiras disciplinares no próprio contexto universitário, para, desse modo, contribuir para que a universidade cumpra seu papel de instituição fundada na reflexão e no debate críticos sobre e na produção do conhecimento (CHINELLI et all 2016, p. 20).

A partir e compondo essa trajetória do PIBID na UFF, cada área do conhecimento vem com sua história e singularidade. Seguimos esse texto, trazendo a Educação Física.

\section{A formação de professores de Educação Física no contexto de tensões}

Mencionar a Educação Física nesse contexto de tensões em que encontramos o PIBID requer, antes, explicitar com qual perspectiva a identificamos e, na sequência, os conflitos que marcam a sua constituição na escola e na formação de professores - em geral e no específico da área. Nesse exercício de pensar a organização e a formação docente para essa prática pedagógica, aqui apresentamos a educação física escolar indagando a obviedade de como é conhecida e, ao mesmo tempo, consideramos que essa apresentação contém a dinâmica da “arte 
de fazer algo existir, a arte de dar autoridade a um pensamento" (MASSCHELEIN; SIMONS, 2014, p. 135).

Para isso, aqui não entraremos em sua trajetória histórica, mas partiremos do marco que é a concepção de cultura corporal, a qual surge, no Brasil, como essa nomenclatura, no final dos anos 80, por um Coletivo de Autores (2014), em pleno momento de abertura política, após vinte e um (21) anos de ditadura civil-militar. Com as inquietações, tensões e forças desse contexto sócio-político, a cultura corporal surge como concepção norteadora dessa área, possibilitando, pela primeira vez após sua entrada no universo escolar, explicitar que essa prática pedagógica contém objeto de conhecimento, com intenções e objetivos escolares (e por isso sua inserção na escola e sua vinculação com as ideias dessa instituição - e não mais com a médica e/ou militar, como muitos ainda advogam) e; assim, desloca seu foco da aptidão física (o qual ainda está presente em muitas orientações e visões voltadas para a educação física).

Pela forma da cultura corporal, a educação física retira o corpo e as práticas corporais do estritamente biológico (que recebe o apoio da aptidão física, como concepção) e; como objetos de estudos, os apresenta aos alunos como conteúdos e, no envolvimento atento com esses conhecimentos, os alunos poderão perceber aspectos que também são da história, da filosofia, da antropologia, do artístico etc.. No tratamento pedagógico desses conteúdos, a organização do trabalho contribuindo para que os alunos não fiquem restritos ao que "gostam", "sabem" ou "acham" importante. Pois

O homem não nasceu praticando esporte, muito menos relacionando esporte com saúde, mas adquiriu, pelo trabalho, pelas atividades, as condições de produzir e reproduzir seu modo de vida onde as relações esporte e saúde [por exemplo] foram se consolidando. Essa construção passa pelas relações do homem com a natureza e com os outros homens na manutenção da vida humana. Aí se constrói a cultura corporal - jogos, esportes, dança, ginástica, lutas e outras formas que tratamos pedagogicamente na escola (COLETIVO DE AUTORES, 2014, p. 163)

Assim, compartilhamos que o norte orientador na formação docente desenvolvida pelo Instituto de Educação Física da UFF está apoiado no que a cultura corporal possibilita pensar a organização dessa prática pedagógica e sua inserção no escolar. A começar por uma pergunta aparentemente banal, quando o Coletivo de Autores indaga "o que é uma prática pedagógica"? (p. 50), ao abordar o histórico da educação física. Em uma área de formação docente que recebe, a cada ano, inúmeros novos (e jovens) alunos que iniciam sua graduação buscando 
aprimoramento físico nos esportes, almejando o trabalho como técnicos esportivos e/ou treinadores de alto rendimento atlético, essa ainda nos é uma pergunta cara. Especialmente quando, na obra, esse Coletivo responde que “(...) surge de necessidades sociais concretas (...)” (idem). Nada que nenhum livro razoável de didática não possa mencionar. Mas, quando, em 1992 essa obra defende uma “(...) visão histórica que traz a atividade prática do homem, o trabalho e as relações objetivas materiais reais do homem com a natureza e com outros homens, para o centro do sistema explicativo [, trouxeram] a prática do homem para a explicação do que" (p. 124) é a prática pedagógica educação física, ajudando a deslocar da ideia com a qual a maioria dos graduandos chega nas Universidades (as quais, em sua maioria, concordam e atendem essas expectativas...).

Para esses autores, então, a educação física é pensada como elemento da cultura. Falar em cultura corporal, hoje, não é percorrer o caminho da "idolatria do corpo" ou, de que há, em contraposição ou complementação, uma “cultura mental” ou uma “cultura intelectual”. Mas de um corpo que se faz, não idealisticamente, presente no mundo - o que denominamos de corporeidade (CARVALHO, 2012). Nesse sentido, a formação do/a Professor/a não se orienta por competências e habilidades parciais (isso segue a ideia de aptidão física), mas por considerar as maneiras de vida, de estarmos atentos às urgências da dinâmica social, sem descuidar do específico que realizamos nas escolas - como convida a pensar as diversas formas com que as práticas corporais vêm se materializando, ao longo da história.

Porém, em uma sociedade que a tudo e todos naturaliza, as ideias provocadas pela cultura corporal não podem ser consideradas como óbvias. A naturalização da vida, com base nas ciências biológicas, mantendo as pessoas em seus ambientes - no sentido de restringir a vida aos significados da reprodução da sua existência - e, nesse processo, impedem o entendimento de que aprendemos, de acordo com nossas condições e inserção no mundo, a expressar, valorar, identificar as marcas corporais. Questões como gênero, etnia, volume muscular, idade etc., têm sua força e relevância social ignorada e percebida como questão "natural".

Hoje, com base nas ciências humanas, temos condições de formular essas ideias, indicando diferentes caminhos para a inserção da educação física nas escolas, mas a força e a influência da aptidão física permanecem hegemônicas em nosso cenário educacional e social, especialmente em momentos como Olimpíadas, Copa do Mundo de Futebol e campeonatos de expressão regional e nacional, cuja repercussão negativa do Brasil ou da região específica faz 
aparecer na mídia a pergunta: “e o que a educação física tem feito nas escolas?” - com a ideia, ainda presente, de que deveria ser preparatória e selecionadora de grandes e expressivos atletas. Selecionadora, portanto, de talentos. Masschelein e Simons (2014) destacam o quanto a "forma mais sutil de naturalização com um efeito de domação seja o desenvolvimento de talento. Um talento como um conceito se refere às diferenças na predisposição entre os alunos” (p. 117). Talento, dom, performances, habilidades, competências são ideias e gestos presentes nas escolas e na educação física que se orienta pela perspectiva da aptidão física.

Por mais que esse elemento curricular tenha capacidade argumentativa de que busca, pela perspectiva da cultura corporal, o desenvolvimento humano e não o motor (pois esse traz visão fragmentada e a-histórica de corpo); de que o corpo e as práticas corporais são constituídos nos diversos tempos e espaços sociais - e, por isso requerem aprendizagem, cuidado e atenção para sua manutenção e possível alteração -; reconhecemos que encontramos grandes obstáculos no tratamento à educação física escolar, como indica a tentativa de mudança no PIBID em 2016, quando some do Programa, embora tenhamos exemplos de sua potência no escolar.

Essa tensão (aptidão física? cultura corporal?) também está presente na formação docente dessa graduação. Possivelmente, uma das formas de "resolver" essa questão justifica termos por um lado a licenciatura e, por outro, o bacharelado. As diversas formações de professores já têm essa característica, porém nessas, a diferença está naqueles que almejam trabalhar nas escolas (licenciados) e àqueles que querem trabalhar com pesquisa (bacharéis). Sem entrar no mérito dessa discussão, no caso da educação física, licenciado é àquele que atua na escola e, bacharel àquele que atua em clubes e academias (e nesses espaços, para nós, ministrando aulas - embora alguns digam que não, que preparam plano de condicionamento). Assim, professor/a é o licenciado e bacharel identificado como "educador físico". Disso, avaliamos que essa situação provoca uma confusão maior ainda, talvez um desserviço aos professores em diferentes âmbitos (formal, não formal, informal) e, que programas como o PIBID, que se originou com base na formação docente e na valorização do magistério, auxiliam a caracterização da educação física com e no escolar.

O Instituo de Educação Física da UFF desenvolve o único Curso de Graduação em Educação Física no estado do Rio de Janeiro, um dos raros no Brasil que tem currículo voltado exclusivamente ao escolar, e não para academias, clubes e esporte de alto rendimento. Do universo escolar, institucionalmente privilegiamos nossos esforços na graduação para a rede 
pública de ensino, assim como na formação continuada de seus professores - um exemplo disso é o fato de estarmos, em 2016, na vigésima sétima turma de um curso latu sensu de Especialização em Educação Física escolar, em um curso iniciado nos inícios dos anos 90; com uma graduação voltada à escola, na qual essa experiência com a especialização possibilitou questionar a graduação hegemônica e seu afastamento das preocupações e valorização do espaço escolar - por isso, a primeira turma da licenciatura inicia em 2007 e finaliza em 2010 e; há pouco concluímos um trabalho de dois anos para pensar o mestrado em educação física, com força nas ciências humanas e no escolar.

Essa trajetória de compromisso com a escola pública nos faz ingressar no PIBID em 2011 e hoje temos uma equipe com três coordenações de área e quarenta e cinco bolsistas envolvidos, além de uma coordenação institucional ser desse Instituto. Nesse espaço de tempo, a realização no PIBID vem gerando nossa inserção nos diferentes níveis e modalidades de ensino, possibilitando afirmar à docência como princípio norteador da Graduação em Educação Física na UFF (CARVALHO; TERRA, 2015). Nesse movimento, destacamos a consideração do tempo necessário à aproximação, inserção, diálogo e compreensão da dinâmica e complexidade do cotidiano escolar inserido. $\mathrm{O}$ que significa que, em quase todas as unidades escolares envolvidas com esse subprojeto, levamos tempo para conquistar a confiança e estreitar as relações de trabalho, possibilitando a realização das ações previstas: observação e diagnóstico da realidade escolar; relação teoria/prática e o trabalho interdisciplinar; planejamento e sistematização de conhecimentos sobre a prática pedagógica; ações pedagógicas e estratégias metodológicas para o ensino da educação física inclusiva; compartilhar, regularmente, as ações pedagógicas desenvolvidas e; registro das ações pedagógicas e criação de banco de dados.

Esse tempo é necessário, pois os professores, especialmente nas escolas, são constantemente desqualificados em seu trabalho, responsabilizados pelo que dizem que a escola não realiza - desconsiderando os impactos que as mudanças nas políticas educacionais provocam em cada unidade; o muito de não escolar que se espera do trabalho docente; assim como a não valorização plena do magistério. No ensino superior também somos atingidos, pois uma coordenação de área acompanhar três escolas em muito dificulta um trabalho com respeito ao tempo mencionado para estabelecer trabalho de parceria, sem reproduzir lógicas que hierarquizam sujeitos e saberes e, com a presença constante em cada unidade escolar. Assim como o reduzido de coordenadores institucionais, para acompanhar todos os projetos. 
A presença dos Licenciandos e Coordenadores de áreas, nos cotidianos da Educação Básica favorece a aproximação e parceria com a Universidade ao longo do processo acadêmico das unidades escolares, questionando a lógica de "falar sobre" a escola, em momentos pontuais (questionários, coletas de dados para pesquisas etc). Essa relação possibilita a iniciação dos graduandos, de forma coletiva, na organização do trabalho docente e, ao mesmo tempo, que a formação continuada, dos Professores Supervisores e Coordenadores de áreas, aconteça tornando, assim, o PIBID como programa responsável pela formação permanente, não só inicial. A formação inicial, ganha oportunidade singular de estar com a escola, aprendendo a situar-se como Professores, conhecendo, problematizando e propondo para as situações que existem. E, a importância além da formação em serviço, que o PIBID promove, muitos professores supervisores passam a desejar/ ingressar na pós-graduação - o que faz a formação continuada e a inicial serem, cada vez mais, vistas como processo inseparável. Assim como muitos Licenciandos, bolsistas PIBID, realizam seus TCCs (Trabalho de Conclusão de Curso) relacionados à essa experiência e, é crescente o número de professores envolvidos com a pósgraduação pesquisam o PIBID - o que, em breve espaço de tempo, muito favorecerá a avaliação desse processo. No Encontro Nacional de Didática e Prática de Ensino de 2014, em Fortaleza, na mesa em que esteve presente, o Professor Miguel Arroyo chamou atenção para o número de trabalhos (comunicação oral e pôster) sobre o PIBID que estavam sendo apresentados na ocasião.

O diálogo, a observação, a parceria com as escolas participantes trazem inúmeros impactos, especialmente na valorização do magistério, pois as escolas sentem-se fortalecidas com a presença de professores e licenciandos da Universidade; os Professores Supervisores, como co-formadores, reconhecidos pelo que sabem e realizam, tornam-se mais motivados à participação na unidade escolar e em sua formação continuada e; os graduandos são inseridos nessa dinâmica de ação coletiva. Inclusive, a bolsa direcionada à graduação desperta escolha pela Licenciatura em algumas universidades, no caso da Educação Física, do bacharelado para a licenciatura) e favorece que o Professor em exercício possua tempo e condições para estudo.

Em médio e longo prazo, essa relação dialógica com as unidades escolares, favorece o trabalho coletivo, através do diálogo com as demais disciplinas curriculares, em diversos momentos do cotidiano escolar (sala dos professores, conselhos de classe, reuniões para planejamento, momentos de entrada e saida, etc.) - o que muito favorece uma formação de professores de forma interdisciplinar, com trabalho coletivo, em movimento que contribui para 
conhecer as especificidades e conteúdos das demais áreas. Viver um turno na escola - não apenas o momento da aula -, planejar coletivamente, avaliar ao longo do processo vem sinalizando a importância do estudo como parte do trabalho docente. $\mathrm{O}$ que pode auxiliar no realizado em cada Licenciatura, não somente na educação física.

A avaliação, permanente, junto aos Licenciandos, Professores/as Supervisores/as, Alunos/as e Direções das escolas parceiras vem afirmando a continuidade do Programa. Os/As Licenciandos/as com maior segurança na atuação de futuro/a docente, exercitando ver as dificuldades como suas; os/as Supervisoras/es mais fortalecidas e empolgadas com a presença dos/as Licenciandos/as; os/as Alunos/as e Direções das escolas, pela especificidade e natureza da Educação Física, alguns mais do que outros, mas todos com alguma abertura para ouvir, ampliar e desmitificar as expectativas iniciais, em relação ao desenvolvimento das aulas (especialmente quando o esperado está na lógica dos esportes, em sua forma competitiva e/ou que os Licenciandos, junto com as Coordenações de áreas, cheguem às escolas com as soluções para as dificuldades presentes.

Todo esse processo aumenta o compromisso, a responsabilidade e a presença de todos os envolvidos, quando responderam à edital público para assumir bolsa no programa. Caso contrário, a inserção do PIBID poderá favorecer o "senso comum" do que é esperado em cada disciplina e, ampliar a fragilidade que existe em alguns cotidianos, em termos de gestão - o que inclui a esfera pública federal. Com essa perspectiva seguimos e fechamos o texto.

\section{Considerações a partir do realizado no PIBID IEF-UFF}

Todo o aqui mencionado vem afirmando a importância e necessidade da continuidade do Programa, mesmo identificando que há dados, observações e experiências que requerem pesquisas para revelarem a força do realizado. Aqui mesmo, trazemos alguns dados sobre o programa e a área que merecem discussão e avaliação coletiva.

No subprojeto educação física, que compõem o PIBID da Universidade Federal Fluminense, surgem elementos que vem sendo compartilhados com todo o departamental, pois envolve sugestões de modificações e/ou inclusões na matriz curricular em curso. Como a formação inicial para a Educação de Jovens e Adultos (EJA) - ainda não temos disciplina que discuta a Educação Física na EJA, perspectiva que favorece uma formação de professores para todos os níveis e modalidades da Educação. 
Assim como há aspectos relacionados à Pesquisa e Prática de Ensino (PPE) que merecem atenção das diferentes licenciaturas - como a autonomia e criação que a experiência no PIBID vem proporcionando. E, também, com o cuidado em acompanhar ambas ações pedagógica, em movimento que o PIBID não seja uma repetição ou sobreposição às Práticas de Ensino e aos Estágios Supervisionados. Por isso, embora os documentos do programa o priorize no ensino médio, algumas equipes da educação física estão inseridas em realidade em que os graduandos não têm contato (como o caso da EJA) ou há pouco contato em sua formação (como o Curso Normal Médio e anos iniciais do Ensino Fundamental (muitas escolas ao Pedagogo/a cabem todas as ações pedagógicas, inclusive a educação física)).

A relação com a formação inicial e permante de professores requer mencionar e discutir as condições para desenvolver o trabalho docente, o que inclui os momentos de planejamento e estudo. Por isso a valorização do magistério, para nós, é a maior meta do Programa. E, em cenário de possíveis e profundas intervenções nesse programa, ao encerrar esse texto e, o escrevendo como parte do trabalho de continuidade da força da formação em seu desenvolvimento, registramos algumas sugestões, como a construção de processo e instrumentos para avaliação, através de cada Coordenação Institucional, junto às escolas envolvidas com o PIBID desenvolvido - somente assim teremos condições de avaliar o que foi efetivamente realizado, nesse período de existência do programa, o qual, pelo subprojeto em que estamos envolvidas, há elementos importantes quando se trabalha com a intenção de qualificar o que as escolas, formações docentes e políticas públicas realizam para a efetivação de uma escolarização que queremos para todos, na qual todos os conhecimentos estejam presentes.

\section{Referências}

CARVALHO, Rosa Malena. Corporeidade e Cotidianidade na Formação de Professores. Niterói: Editora da UFF (EdUFF)/FAPERJ, 2012.

CARVALHO, Rosa Malena \& TERRA, Dinah (orgs). Educação Física Escolar $-a$ contribuição do PIBID. Curitiba: CRV, 2015.

CHINELLI, Maura Ventura; GOMES, Anne Michelle Dyzman; TERRA, Dinah Vasconcellos; YAMASAKI, Alice Akemi. Didática e formação de professores no PIBID da 
$U F F$ : entre o tangível e o intangível na construção de uma educação inovadora. Curitiba: CRV, 2016 (prelo).

COLETIVO DE AUTORES. Metodologia do Ensino da Educação Física. $2^{\mathrm{a}}$ ed. $3^{\mathrm{a}}$ reimpressão. São Paulo: Cortez, 2014.

GATTI, B.A. et al. Por uma política nacional de formação de professores. São Paulo: Editora Unesp, 2013. p.23-54.

GATTI, Bernadete; ANDRÉ, Marli E. D. A.; GIMENES, Nelson, A. S.; FERRAGUT, Laurizete. São Paulo: FCC/SEP, 2014.

MASSCHELEIN, Jan; SIMONS, Maarten. Em defesa da escola - uma questão pública. $2^{\mathrm{a}}$ ed. Belo Horizonte: Autêntica, 2014.

NÓVOA, A. Para uma formação de professores construída dentro da profissão. Revista Educación, n. 350, set.-dez. 2009. Disponível em:

<http://www.revistaeducacion.mec.es/re350_09.html>

\footnotetext{
${ }^{\text {i }}$ Professora Associada III no IEF/UFF/; coordenadora de gestão do PIBID-UFF; Coordenadora do Grupo de Pesquisa em educação Física Escolar e Formação Profissional.

ii Professora adjunta no IEF/UFF; Bolsista CAPES (pós-doutorado na Universidade de Barcelona); Coordenadora colaboradora da área Educação Física do PIBID-UFF; Coordenadora do Grupo de Pesquisa ELAC (Educação física escolar, experiências Lúdicas e Artísticas, Corporeidades);
} 